\title{
Bemerkungen zur Umschrift
}

Die Umschrift der persischen Wörter und Namen erfolgte nach den Transkriptionsregeln des Tübinger Atlas des Vorderen Orients (Register zu den Karten, Bd. 1, Einleitung A-G, Dr. Ludwig Reichert Verlag, Wiesbaden 1994). Die Längung (und Betonung) der Vokale wurde durch einen waagerechten Strich über dem Buchstaben wiedergegeben. Eine Ausnahme bilden Zitate sowie im Deutschen geläufige Namen (insbesondere Khomeini) und Ländernamen (z.B. Iran statt Īrān). Pluralbildungen werden, wo es aus Gründen der leichteren Lesbarkeit angebracht ist, entsprechend der deutschen Schreibweise wiedergegeben ( z.B. Anğomāns statt Anğomānhā). Russische Eigennamen wurden, wo immer es angebracht schien, ebenfalls transkribiert.

Für die deutsche Übersetzung der persischen Begriffe wurde das Persisch-Deutsche Wörterbuch von H. Junker und B. Alavi (4. Aufl., Leipzig 1965) verwendet. 